\title{
Pome fruit health
}

\author{
Dieter Treutter
}

Published online: 18 January 2012

(C) Springer-Verlag 2012

The pome fruits, apple and pear, represent very important fruit crops in Europe. They are grown on 490,000 ha in 15 countries with a production of more than 11 million tons per year (FAO, 2003). This corresponds to an estimated annual value of $€ 20$ billion at consumer prices. European consumers are highly concerned about health and safety aspects of food. High quality fruits in sufficient amounts can only be produced on healthy plants. Thus, one of the most important tasks in crop production is an effective and sustainable management of plant diseases.

Two of the most important diseases in European pome fruit growing are fire blight which is caused by the bacterium Erwinia amylovora, and the scab on apple and pear caused by the fungi Venturia inaequalis and $V$. pirina, respectively. Erwinia species cause not only severe losses in apple and pear but also attack numerous native wild species and popular ornamentals of the Rosaceae. Intensive investigations on these pome fruit diseases revealed new insights into the molecular aspects of the host-pathogen interactions, into possible mechanisms of defence by the host plants, into the genetic background of plant resistance and tolerance and into the molecular basis of virulence.

Nowadays, nearly all European countries are facing similar problems regarding plant protection in pome fruit growing. Thus, co-operation at the international level is required and a network of more than 200 European scientists from 25 countries was established by the COST action 864 'Combining traditional and advanced strategies for plant protection in pome fruit growing' (Acronym

D. Treutter $(\bowtie)$

Unit Fruit Science, Technische Universität München,

Dürnast 2, 85354 Freising, Germany

e-mail: dieter.treutter@wzw.tum.de
POME FRUIT HEALTH). The action focused on different aspects includes the (i) investigation of plant-pathogen interactions, (ii) germplasm resources and breeding, (iii) production methods and (iv) biotechnological resources.

This special issue of Trees provides an overview of the fruitful yield of the interactions among European experts. A series of reviews and original articles cover actual research topics mainly in the fields of germplasm resources and breeding, host-pathogen interactions and fruit tree protection.

For breeding, it is crucial to identify germplasm with heritable disease resistance. The development of efficient markers is essential for marker-assisted selection which is already used in breeding programs for scab resistance but is also attempted for fire blight resistance. Resource evaluation must include the susceptibility to fire blight (E. amylovora) and scab ( $V$. inaequalis, $V$. pirina), but also to other diseases such as powdery mildew (Podosphaera leucotricha), pear rust (Gymnosporangium sabinae), brown spot of pear (Stemphylium vesicarium) and storage diseases (e.g. Penicillium expansum and Monilinia spec.). The knowledge of the genes behind a resistance and of its mode of action improves breeding success and offers prospects in gene technology. Recent advances are reviewed for the Vf resistance of apples against the scab. The possible involvement of secondary plant metabolites such as phenolic compounds in the defence of $V$. inaequalis is still debated. Various floral traits that may play a role in the onset and progression of E. amylovora infection are compared between susceptible and tolerant apple and pear varieties and the expression pattern of stress-related genes in E. amylovora-infected pear leaves is shown. It is not the core scope of Trees to deal with bacteria. However, it completes the examination of fire blight management. For progress in pome fruit protection against this bacterial 
disease, suitable detection tools are essential which provide epidemiological information. Comparative studies on the genomes and plasmids of Erwinia and related species contribute to further understanding of pathogenicity or epiphytic biology. Modern fire blight management strategies include the application of chemical compounds which are toxic against the bacteria or may increase plant resistance as well as biological control using antagonistic microorganisms.

We hope that this special issue may arouse interest in the reader of Trees and particularly in those who are interested in fruit trees. It is our intention to present basic principles of plant protection in pome fruit growing by way of examples of important diseases and respective recent advances in research. It is the merit of the project coordinators Dr. Heidi Halbwirth and Prof. Dr. Karl Stich from Technical University of Vienna that many European scientists cooperated under the umbrella of the COST action 864. Finally, we want to express our gratitude to the European Cooperation in Science and Technology (COST) which enabled the dissemination of the COST 864 outcome by 7 "open choice" review articles.

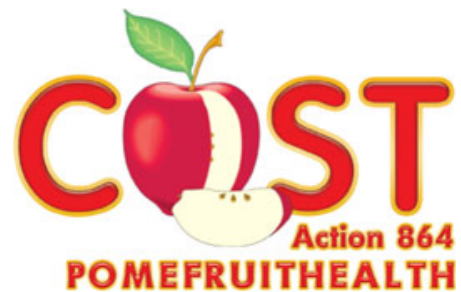

